\title{
The Boundary-Spanning Role of First-Tier Suppliers in Sustainability- Oriented Supplier Development Initiatives
}

\begin{abstract}
Purpose: To study how first-tier suppliers (FTs) operate as boundary-spanners between the focal firm and second-tier suppliers (STs) in extending sustainability-oriented supplier development (SSD) initiatives up the supply chain.

Design/methodology/approach: An exploratory multi-case study approach in the apparel industry is adopted, comprised of four cases focused on occupational health and safety (OHS) issues. The paper uses primary semi-structured interviews and observation data and secondary documents; and it is informed by boundary-spanning and social capital theory.

Findings: The influence of downstream social capital on the upstream boundary-spanning actions of FTs is highlighted. More specifically, it is found that the cognitive and relational capital that exists in the downstream relationship between a FT and the focal firm affects whether the FT adopts compliance-oriented or improvement-oriented boundary-spanning actions in their upstream relationships with STs. Particularly important aspects of cognitive and relational capital are highlighted while the phenomenon of FTs adding their own personal interpretation to sustainability requirements when fulfilling their boundary-spanning role is identified.
\end{abstract}

Research implications: A distinction is made between compliance-oriented and improvement-oriented boundary spanning actions. A deeper insight into the boundary-spanning role of FTs in extending SSD initiatives up the supply chain to STs is provided along with a deeper understanding of how this role is impacted by social capital.

Practical implications: Focal firms should seek to build adequate cognitive and relational capital with their FTs before deploying SSD initiatives in order to extend their reach further upstream in the supply chain. In doing so, it is also important to be cognisant of the social capital that exists between FTs and STs.

Originality/value: The paper contributes to the SSD literature by going beyond the buyer-FT dyad to examine the FT's boundary-spanning role in the wider buyer-FT-ST chain relationship. The study theoretically and empirically draws out the importance of relation-specific assets through the social capital lens.

Keywords: Sustainability-oriented supplier development; multi-tier supply chains; boundary spanning; social capital theory.

Paper type: Research paper 


\section{Introduction}

Focal firms are facing increasing pressure from external stakeholders, including nongovernmental organisations (NGOs) and regulatory bodies, to enhance the sustainability of their supply chains (Grimm et al., 2014). Consequently, many have proactively undertaken sustainability-oriented supplier development (SSD) initiatives. These initiatives expand the focus of traditional supplier development - aimed at improving economic and operational performance - to incorporate the goal of improving supplier social and/or environmental performance (Busse et al., 2016; Liu et al., 2018). It has been argued that SSD can enhance the entire chain, as supply chains that integrate social and environmental resources are more difficult to replicate, providing a competitive advantage of benefit to all firms (Carter and Rogers, 2008).

Achieving a truly sustainable supply chain, where SSD initiatives cascade to lower-tier suppliers, remains very challenging (Wilhelm et al., 2016; Villena and Gioia, 2020). Indeed, complex supply networks, characterised by an absence of direct control (Tachizawa and Wong, 2014), a lack of information transparency, and limited public scrutiny (Mena and Schoenherr, 2020; Villena and Gioia, 2020) make it difficult for focal firms to directly access lower-tier suppliers where the most serious sustainability violations often occur (Sauer and Seuring, 2018; Soundararajan and Brammer, 2018). Yet external stakeholders frequently hold focal firms responsible for any sustainability issues along their supply chains (Grimm et al., 2014). For example, big brands such as Nike have suffered huge reputational losses due to non-adherence detected in their lower-tier suppliers (Grimm et al., 2014; Villena and Gioia, 2020). These reputational losses have occurred despite Nike claiming to have undertaken substantial efforts to enhance suppliers and support their development (Nike, 2020).

In general, three main options have been discussed and applied to manage the sustainability of multi-tier supply chains, i.e. direct control, relying on first-tier suppliers, and working with a third party (Tachizawa and Wong, 2014). Given the difficulties associated with directly engaging with lower-tier suppliers, focal firms may be more likely to recruit first-tier suppliers (FTs) and third parties, both of which can play an intermediary role in working directly with the lower tiers (Grimm et al., 2014; Soundararajan and Brammer, 2018). Indeed, recent research has highlighted the importance of FTs for disseminating sustainability requirements upstream. For example, Wilhelm et al. (2016) identified contingency factors affecting whether FTs engage in undertaking this so-called boundary-spanning role, including the focal firm's use of power. In this role, FTs act as the disseminator and monitor of sustainability standards whilst also acting as the assimilator of knowledge, thereby providing assistance to lower-tier 
suppliers. Such a role has been found to be dependent on how FTs interpret sustainability requirements and take actions, but the antecedents explaining how FTs configure their role remain under-explored (Soundararajan and Brammer, 2018).

Disseminating sustainability is partly voluntary in nature, making it reliant on the presence of social capital - an important relation-specific asset derived from network relationships that consists of three dimensions: structural, cognitive and relational capital (Nahapiet and Ghoshal, 1998; Zhu and Lai, 2019). As an example, relational capital, such as in the form of trust between the focal firm and its FTs, has been found to play a particularly crucial role in achieving successful multi-tier supplier management in terms of sustainability (Grimm et al., 2014). Furthermore, social capital can influence value creation by affecting the accessibility, anticipation, motivation and exploitation capability of knowledge transfer (Nahapiet and Ghoshal, 1998). It is argued here that the social capital between the focal firm and first tier may affect the way in which FTs fulfil their boundary-spanning role in extending SSD initiatives up the chain. This however requires empirical investigation; hence, this research seeks to address the following question:

RQ: How does the social capital that exists between a first-tier supplier and a downstream, focal firm affect the way in which the first-tier supplier fulfils its boundary-spanning role in disseminating SSD initiatives to upstream, second-tier suppliers?

To address this research question, we adopt a case study approach in the context of a social SSD project focused on Occupational Health and Safety (OHS) issues, as deployed by one focal firm in the apparel industry with its FTs and second-tier suppliers (STs). Social misconduct remains largely invisible, and some suppliers are known to have undertaken superficial actions to 'mock comply' with strict auditing and certification requirements (Huq and Stevenson, 2020). Such a situation makes it especially important to investigate how lower tiers can be successfully engaged in SSD. The main contribution of this research is in drawing out the impact of social capital on refining and substantiating the boundary-spanning role of FTs related to SSD. The findings inform decision-makers in focal firms about the importance of building adequate cognitive and relational capital with FTs in order to reap the full benefits of SSD initiatives.

The remainder of this manuscript is organised as follows. The theoretical background is provided in Section 2 before Section 3 outlines the research method. Section 4 provides a detailed description of the empirical findings, followed by a discussion in Section 5. Finally, conclusions, implications and future research directions are outlined in Section 6. 


\section{Theoretical Background}

The theoretical background is organised into three sections. SSD is first defined, followed by a summary of key constructs from the boundary-spanning literature and their application in the context of SSD. The final subsection defines social capital and outlines its relevance to SSD.

\subsection{Sustainability-oriented supplier development (SSD)}

Supplier development (SD) initiatives in general refer to efforts made by the focal firm that go beyond the explicit buyer-supplier contract to enhance a supplier's capability to accrue performance benefits, such as reduced costs and improved quality (Krause et al., 2007). They are typically divided into direct and indirect SD initiatives based on the involvement level of the focal firm, the extent of their investment, and the goal of the SSD initiative (Zhang et al., 2017). Direct initiatives are considered better for improving suppliers' capabilities and include practices such as training and on-site consultations; whilst indirect initiatives are widely applied to ensure basic compliance, including providing improvement incentives and conducting audits (Krause et al., 2007; Zhang et al., 2017). The extant literature specifically on SSD has extensively examined the managerial practices employed to develop FTs and the associated outcomes of these practices (Rogers et al., 2019); but most of this work has been from the focal firm perspective.

In the context of multi-tier SSD initiatives, the focal firm is often dependent on FTs in extending SSD initiatives up the supply chain using their direct contractual relationships with both the focal firm and STs (Grimm et al., 2014). Focal firms provide assistance to this endeavour by developing the FTs' ability to assume responsibility for developing STs through SSD initiatives (Busse et al., 2016; Mena and Schoenherr, 2020). However, no prior research has looked closely at how and why FTs take on this responsibility. We will unpack this further using boundary-spanning and social capital theory literature, as introduced below.

\subsection{Boundary-spanning role in the context of SSD}

Boundary theory argues that "a central task of organisations is to manage their boundaries with other organisations that supply critical resource inputs or are responsible for the disposal of their outputs" (Zhang et al., 2011, p. 319). Boundary-spanning includes both individual and organisational level actions, where individual actors play an important role in maintaining micro-macro linkages (Schotter et al., 2017). Different boundary-spanners that are assigned boundary-spanning work sit on the boundary of an organisation, supporting organisational functions and maintaining effective links with elements of the environment, e.g. with business 
partners (Aldrich and Herker, 1977). In the context of a buyer-supplier exchange, purchasing agents or departments from the focal firm, for example, are responsible for interactions and coordination with salespersons or the sales department from the supplier firm to support the purchasing strategy and maintain the exchange relationship (Zhang et al., 2011).

The boundary-spanning role can also be carried out by individuals or groups who are not officially assigned this responsibility (Schotter et al., 2017). For example, in the context of multi-tier supply chains, sustainability staff or the sustainability departments from the FTs not only fulfil the requirements of the focal firm but also take on the responsibility of diffusing those requirements to STs (Wilhelm et al., 2016). Therefore, FTs, as non-traditional boundaryspanners that are independent of the organisation they both represent (focal firm) and target (ST), assume responsibility for carrying out boundary-spanning actions by exploiting their unique position of being at the boundaries of both the upstream and downstream dyads.

Boundary-spanning specifically regarding sustainability in a multi-tier supply chain context can be challenging. First, it requires goal alignment between the purchasing and sustainability functions in the focal firm; otherwise, FTs may disengage from the boundary-spanning role (Wilhelm et al., 2016). Second, as an independent organisation, sustainability staff from FTs have been found to interpret the sustainability requirements of the focal firm in a positive or negative way, leading to either supportive or unsupportive boundary-spanning actions, respectively (Soundararajan and Brammer, 2018). More specifically, some FTs interpret the requirements as an opportunity to improve STs' capabilities and therefore engage in supportive procedures, such as constructive dialogue and knowledge sharing events; but others adopt a threatened, defensive attitude and engage in more limited dialogue and knowledge sharing (Soundararajan and Brammer, 2018). Soundararajan and Brammer's (2018) research presented the dichotomy between adopting a positive or negative boundary-spanning role when diffusing sustainability requirements up the supply chain. Further, the authors suggested that future research should examine how this role varies across different contexts as this may result in the focal firm imposing their requirements in different ways.

Specifically in the context of SSD, where the goal can be either to pursue improvement or achieve compliance (Zhang et al., 2017), technical assistance and knowledge sharing from the focal firm have been found to positively affect the behaviour of FTs and the actions they take (Mena and Schoenherr, 2020). Therefore, it is argued that the boundary-spanning role of FTs can be organised into two categories, i.e. compliance-oriented and improvement-oriented. The compliance-oriented boundary-spanning role is associated with actions such as sharing information with STs that is exclusively relevant to the audit (Grimm et al., 2014; Zhang et al., 
2017) in order to achieve compliance with local and/or international requirements. In contrast, the improvement-oriented boundary-spanning role aims to go beyond compliance to pursue further improvements, and hence this includes actions such as dedicated training and consultancy sessions, and joint actions intended to achieve the improvement goals set out by SSD (Busse et al., 2016; Zhang et al., 2017; Soundararajan and Brammer, 2018). We reason that such a categorisation better fits the SSD context than a straightforward positive versus negative distinction (Soundararajan and Brammer, 2018). This is because compliance-oriented actions imply a certain degree of dialogue and knowledge sharing - even if this is only relevant to achieving compliance - and thus they too can make a positive contribution (towards meeting audit requirements).

\subsection{Social capital theory and its relevance to SSD}

SSD provides a platform for knowledge transfer and diffusion to occur, enabling FTs to acquire new knowledge and leverage it to improve sustainability within their firms and suppliers (Villena and Gioia, 2020). Prior research has shown that social capital can influence how suppliers practice sustainability in buyer-supplier relationship networks (Zhu and Lai, 2019; Alghababsheh and Gallear, 2020). Thus, in the context of multi-tier SSD initiatives, the way in which FTs leverage the knowledge gained via SSD to practice boundary-spanning actions towards STs may depend on the social capital built in their relationship with the focal firm.

Social capital, in general, can be further divided into three distinct dimensions - structural, cognitive, and relational capital - that differ from each other in terms of how they affect knowledge transfer and development (Nahapiet and Ghoshal, 1998). First, structural capital is generated from the ties between members within a network. Second, cognitive capital, including shared language and codes, and shared values and goals, provides shared representation, interpretation and systems of meaning among parties. Third, relational capital is concerned with the resources derived from personal relationships formed through past interactions, which usually includes norms, trust and reciprocity, and identification (Nahapiet and Ghoshal, 1998; Inkpen and Tsang, 2005; Krause et al., 2007). Definitions of the different aspects of each social capital dimension are provided in Table I. All three dimensions can contribute to providing accessibility to, and clarifying the purpose of, knowledge transfer; however, the motivation to leverage knowledge is determined exclusively by relational capital, and the ability to exploit knowledge is derived from cognitive capital (Nahapiet and Ghoshal, 1998). 
In general, social capital plays a critical role in supply chain management (Zhang et al., 2017), and social capital theory has been increasingly applied in supplier development research (e.g. Krause et al., 2007; Preston et al., 2017; Alghababsheh and Gallear, 2020). Prior research has attempted to distinguish between the three dimensions of social capital and their relative power, with relational capital being found to have a more substantial impact than the other two dimensions, especially when the buyer-supplier dyad is pursuing strategic goals (e.g. Villena et al., 2011). Meanwhile, Preston et al. (2017) found that suppliers with a stronger ability to exploit the knowledge transferred upstream can gain greater benefits. Further, recent research in the field of sustainable supply chain management has found that social capital affects the sustainability practice and performance at the supplier side (Zhu and Lai, 2019). No prior research, however, has examined how social capital within the buyer-supplier dyad affects the knowledge transfer that takes place during SSD. Thus, this research aims to explore this phenomenon by studying how social capital within the buyer-FT dyad affects the upstream boundary-spanning work of FTs in the context of SSD.

\section{Research Method}

The nascent state of the literature on the boundary-spanning role of FTs in SSD calls for an exploratory study. We thus develop and elaborate on the limited available literature using case study research. Case research is especially suitable as it allows for a thorough examination of complex, real-life issues with little prior empirical evidence, potentially leading to new, indepth insights (Barratt et al., 2011; Huq and Stevenson, 2020). Further, the case study method enables researchers to collect rich data from multiple sources, such as interviews, observations and documents to support triangulation (Barratt et al., 2011). We have adopted a multi-case study design, made up of four cases, allowing for depth but also breadth of exploration to achieve our aim of theory development and elaboration following abductive reasoning (Ketokivi and Choi, 2014; Voss et al., 2016). Four measures of research quality from Yin (2018) were applied to the research design, as summarised in Table II and used in case study exemplars from the SSD literature (e.g. Rodríguez et al., 2016).

\section{[Take in Table II]}

\subsection{Research context and case selection}

We have focused on the apparel industry, with a particular interest in FTs operating in China. As a labour-intensive industry, the apparel industry has been under prolonged global scrutiny 
for its sustainability performance (Huq and Stevenson, 2020). Meanwhile, China holds a leading position regarding the production and exportation of apparel, accounting for $30.8 \%$ of world apparel exports in 2019 (World Trade Organization, 2020). Yet, non-adherence to sustainability requirements, including excessive overtime, has been repeatedly detected in Chinese suppliers (Villena and Gioia, 2020), prompting several Western buyers to launch SSD projects across multiple tiers of their supply chains in China (Nike, 2020). We decided to explore the Occupational Health and Safety (OHS) issue as it remains a major social sustainability concern, as highlighted by tragic events such as the Rana Plaza collapse, which has not been sufficiently addressed despite ever-stricter audits (Alghababsheh and Gallear, 2020). In addition, big brands such as Nike have identified OHS issues as one of their top two priority issues to address in the coming years (Nike 2020). It therefore follows that the apparel industry in China provides a rich research setting for conducting empirical research on SSD that is focused on OHS issues.

We grounded our study in an SSD project initiated by a multinational apparel brand (A1) for its suppliers based in China as an important part of the brand's entire SSD agenda. The project included a concentrated two-day training session on OHS issues plus a follow-up onsite consultation for the second-tier suppliers that sought to evaluate whether mandated improvements had been accomplished following the training. The project was chosen because: 1) it was meant to improve suppliers' capabilities in managing OHS issues by providing them with relevant knowledge in a systematic way and with necessary support afterwards, 2) it was deployed by A1 in collaboration with an external knowledge provider (T1) that has expertise in sustainability knowledge and the deployment of SSD projects, and 3) one of the researchers was based in T1 for six weeks covering before, during and after the project, building trust with staff from $\mathrm{T} 1$ and A1 thereby providing the research team with access to this project and opportunities to observe every event.

The case is defined as the boundary-spanning role of FTs in a bid to elaborate our understanding of how FTs practice their boundary-spanning role and how this role is affected by the social capital that exists in the FT-A1 relationship network. Heeding Ketokivi and Choi's (2014) duality criterion of being situationally grounded but at the same time seeking a sense of generality, we selected different cases from the same SSD project context. This choice provided us with the opportunity to observe the contextual idiosyncrasies in this specific context, to ensure consistency and to reduce extraneous variation under the guidance of the theoretical constructs from social capital and boundary-spanning theory (Eisenhardt, 1989; Ketokivi and Choi, 2014). A sense of generality was established by incorporating newly emerged concepts, 
i.e. empirical elaborations, to achieve theory elaboration via abductive reasoning (Ketokivi and Choi, 2014).

We developed a list of potential FTs based on the information provided by A1 and T1 following literal replication logic in order to provide similar and complementary findings (Voss et al., 2016; Yin, 2018). This helps in constructing a whole picture of an under-explored phenomenon, i.e. the boundary-spanning role of FTs. More specifically, we selected FTs that met the following criteria: 1) the FT has been delegated the responsibility from A1 to manage and ensure the compliance of STs, and there is no direct governance from A1 of the STs, 2) the FT is a critical supplier to A1 and has been doing business with A1 for more than five years, and 3) the representatives from both the FT and its STs who attended the SSD project are dedicated staff managing OHS issues within their organisation on a daily basis.

We ultimately secured the acceptance of four FTs (FT1 to FT4) that both proactively participated in the SSD project and were willing to share their insights, leading to four cases. Four cases is within the suggested range of cases for striking a suitable balance between complexity and volume of data in order to reach a satisfactory level of depth of understanding of the phenomenon under study (Eisenhardt, 1989; Barratt et al., 2011). We also gained access to multiple sources of data relating to the four FTs we selected, such as observations throughout the SSD project, including during two STs on-site consultation events, where ST1 supplies FT1 and ST2 supplies FT2.

As discussed in the following sub-section, the data collection methods included, among other approaches, the use of interviews. A purposive sampling method was used to select participants for the interviews. As the unit of analysis is the boundary-spanning role of the FTs, key informants within the A1-FT-ST chain are those who both participated in the SSD project and are in charge of daily communication. We interviewed one such key informant from each FT and from A1, and two such key informants from T1. In addition, we also interviewed one such key informant from each of the two STs that were provided with an on-site consultation.

\subsection{Data collection}

A case study protocol guided the data collection stage. The protocol specified a detailed data collection plan, including the interview schedule, the events to be observed, and the documents to be reviewed when on site (Yin, 2018). The research team had regular interactions with all parties involved in this study before, during and after the SSD project. With the support of T1's staff and a six-week residency in $\mathrm{T} 1$, one researcher was able to carry out observations during the entire project in addition to conducting interviews. Thus, opportunities for data collection 
included interviews, project update meetings, informal conversations, and participation in and observation of the training sessions and on-site consultations. The duration of the interactions varied from the observation of the two-day training session to short, informal conversations with relevant staff during lunchtimes. Thus, multiple sources of data, including interview transcripts, observation notes, and relevant documents such as training materials, provide rich qualitative data and add to data triangulation (Chakkol et al., 2018; Yin, 2018).

Firstly, in terms of the interviews, a total of twelve face-to-face interviews were conducted as follows: A1 (2), FTs (4), T1 (2), STs (2), and two follow-up debriefing interviews with both A1 and T1 after each site visit to the second-tier supplier factories. The interviews focused on two main topics: the boundary-spanning actions of FTs and the interactions among parties within the A1-FT-ST set of relationships. For example, we asked the FTs if and how they were further assisting their suppliers based on the takeaway points from the training. On average, each interview lasted 40 minutes, and all interviews were audio-recorded, accompanied by written-up notes validated by the interviewees, and transcribed, resulting in 151 pages of transcripts. All interviews were conducted in Chinese. Unclear issues were clarified through follow-up online interactions in a chat group created during the training session. Example interview questions for the focal firm, FTs, STs and external knowledge provider are provided in an Appendix.

Secondly, a total of 240 hours of observations were conducted during the six-week residency in T1. More specifically, detailed notes were taken about the communications and actions between the different parties involved in the project, the two-day training and on-site consultations, and during and after the formal interviews. The observation notes focused on recording the interactions, including formal and informal chats between the FTs, A1 and STs, the actions taken by the FTs regarding the dissemination of the SSD initiative and sustainability requirements, and the social capital between the different parties.

Moreover, we reviewed key documents, such as corporate documents, training materials, and test papers, that provided information about the SSD project, the context, regulations, and OHS awareness and practices of the STs. Observation notes and secondary data complemented the interview data and contributed greatly in revealing the social capital residing between the focal firm and FTs and the past actions taken by the FTs. Data collection culminated in two debriefing interviews with A1 and T1. At this point, no new themes were identified; instead, ideas expressed by A1 and T1 had all been documented based on previous interviews and captured in diary notes. Therefore, the four cases were enough to reach a satisfactory level of theoretical saturation. Data collection, therefore, stopped as it was concluded that additional 
data would not have increased our understanding of the research question (Eisenhardt, 1989; Huq and Stevenson, 2020). Figure 1 provides an overview of the firms accessed, the informants interviewed, and the additional sources of data collected.

\section{[Take in Figure 1]}

\subsection{Data analysis procedure}

Data analysis began with reading the transcripts several times to increase familiarity with the data before proceeding to open coding. During the open coding process, data relevant to the actions taken by the FTs to extend the SSD initiative and to the relationship resources between the FTs and the focal firm were coded inductively. This process was supported by qualitative data analysis software (N-Vivo), which facilitated the retrieval and management of data (Rodríguez et al., 2016).

The codes derived from open coding were then collapsed into higher-order codes, which were labelled using established constructs from both boundary-spanning literature and social capital theory. At this stage, we adopted an iterative approach to refining the codes, moving back and forth between relevant theory and data. More specifically, prior theoretical research (e.g. Inkpen and Tsang, 2005) informed the foundations of the research while empirical studies that used the theoretical constructs helped to make sense of them in this context (e.g. Krause et al., 2007). This also helped to establish and refine the link between inductive codes and the constructs from the literature and enabled us to empirically substantiate constructs such as shared values and goals. Moreover, boundary-spanning actions identified were collated with constructs from prior literature and elaborated to fit the research context. We also categorised the boundary-spanning actions identified from our research into two categories to supplement prior research, i.e. compliance-oriented and improvement-oriented actions. Therefore, the coding process was grounded in the qualitative data whilst taking into consideration key concepts from the literature (Ketokivi and Choi, 2014). Figure 2 summarises the coding structure derived from the process.

\section{[Take in Figure 2]}

\section{Findings}

Section 4.1 provides a summary of the boundary-spanning role fulfilled by the FTs, unpacking this into specific boundary-spanning actions. The social capital that exists in the four FT-A1 dyads is then presented in Section 4.2 to explore how this affects FTs' boundary-spanning roles. 
Table III presents examples of the empirical evidence, including illustrative quotes and observation notes.

\section{[Take in Table III]}

\subsection{Boundary-spanning actions}

Based on the discussion in Section 2.2, the boundary-spanning actions taken by the FTs in SSD were categorised into compliance-oriented and improvement-oriented actions, as summarised in Table IV. The table includes actions that had previously been identified in the literature and are supported here by empirical evidence as well as some compliance-oriented actions that are, to the best of our knowledge, presented here for the first time. More specifically, we found that when FTs primarily adopt a compliance-oriented boundary-spanning role, they tend to strike compromises between the focal firm and second tier, mainly to protect the interests of STs and themselves in the context of SSD. Meanwhile, personnel from two FTs were found to add their own personal interpretation when diffusing information to STs, filtering out important content relevant to SSD.

\section{[Take in Table IV]}

From Table IV it can be seen that the four FTs behaved differently when carrying out boundary-spanning actions. In general, both improvement-oriented and compliance-oriented boundary-spanning actions were practiced by all of the FTs except FT2, which only practiced compliance-oriented actions. FT3 adopted a more improvement-oriented boundary-spanning role while the three remaining FTs primarily adopted a compliance-oriented role in the context of SSD. FT3 transparently passed information to STs, proactively engaging in further learning and joint work with STs, and exhibiting an intention to reduce the dissonance between A1 and STs regarding OHS issues. In contrast, although FT1 also transparently transferred knowledge, it focused more on striking compromises between A1 and the STs and did not carry out any proactive actions. Meanwhile, personnel from FT2 and FT4 filtered out information based on their own judgement and interpretation of what needed to be passed up the chain. Yet, FT4 still exhibited a propensity to carry out active learning while FT2 only superficially assisted STs in order to achieve audit compliance. Sections 4.1.1 and 4.1.2 below provide more detailed findings regarding the compliance-oriented and improvement-oriented boundary-spanning actions carried out by the four FTs, respectively. 


\subsubsection{Compliance-oriented actions}

The FTs engaged in knowledge and information sharing events focused on audit-relevant content in a bid to achieve compliance. For example, routine audit-relevant practices such as audit-driven site visits and training sessions intended to ensure the compliance of STs were carried out by all four FTs. This is because the FTs were assigned responsibility for diffusing sustainability requirements to STs and for monitoring their sustainability performance. One of the FTs (FT1-1) mentioned that: "I have visited my STs and helped them with the mandated improvement assignments". Meanwhile, ST1-1 confirmed that "It is always the FTs who directly contact us in terms of OHS issues, he [FT1-1] regularly visited us, especially during audits ... he [FT1-1] came to us after the training session and asked us to finish the assignments".

Further, in terms of knowledge and information sharing via site visits, FT2 and FT4 were found to filter information to STs based on personal interpretation, only diffusing information that they thought would be useful for passing future audits. For example, FT4-1 argued that: "STs do not need to know the underlying reasons and national laws and standards. All they have to know is what and how they must do things in order to pass the audits". Such subjective filtering undermined the impact of the training on FTs and STs as the primary intention of A1 when deploying the SSD project and training sessions - "to help suppliers [both FTs and STs] gradually establish OHS management systems within their firms via SSD projects instead of just passing audits" - was being omitted and therefore not diffused up the chain.

Meanwhile, regarding the consultations and assistance provided to STs after the training session, superficial follow-up actions were exhibited by FT1 and FT2 who provided templates for STs to complete. The templates were prepared based on FTs' understanding and interpretation of the assignments. ST1-1 was aware of the requirements and tried to complete the assignments with assistance from FT1-1; however, he was not able to accomplish the task adequately as both he and FT1-1 had made little effort to assimilate the knowledge delivered during the training. The situation was even worse for ST2-1 who only filled in the forms required based on the templates and sample answers provided by FT2-1, who was found to have misunderstood the requirements. Further, FT2-1 attempted to shield ST2 from the gaze of A1. A1-1 and T1-1 were aware of this and expressed their disappointment, admitting that this approach could not help STs to genuinely improve. During the debriefing meeting, T1-1 explained to A1-1: "As you can see, ... [ST2-1] does not really care about anything from the training, ... [FT2-1] would prepare all materials required on her behalf [ST2-1] and will do cover-ups for her firm [ST2], so ... [ST2-1] did not have the awareness or the intention to take any actions". 
Moreover, when FTs primarily focused on audit-relevant performance they sought to strike compromises mainly for the interest of the STs and themselves and attempted to justify why it is difficult to practically apply the knowledge acquired from the training at STs. This is in contrast to A1's intention behind carrying out the SSD project - a step towards achieving better social conditions for all critical suppliers. Three out of the four FTs, i.e. FT1, FT2 and FT4, complained that the training content was too high-level and theoretical to guide practical solutions to STs' problems or non-compliances. In particular, FT4-1 argued that: "There is a need to tell us how to address the issues our STs have to avoid incidents...for example, we have a problem regarding the use of doors to ensure safety. What we want to know is how to achieve compliance given our current situation instead of being told that it is against the law". Further, FT2-1 stressed the difficulties in meeting the requirements of SSD and sought to justify her actions, such as her provision of templates and sample answers.

\subsubsection{Improvement-oriented actions}

When the FTs carried out improvement-oriented boundary-spanning actions, they engaged in knowledge and information sharing events that were broader in scope than purely audit-driven thinking and that were aimed at pursuing further improvements beyond compliance. More specifically, FT1, FT3 and FT4 were found to go beyond compliance-oriented actions by also carrying out improvement-oriented actions in order to pursue the goal of SSD set by the buyer. For example, both FT1-1 and FT3-1 convey information transparently to STs, as instructed by A1-1, such as by sharing notes and printed materials from the training with STs. Meanwhile, both FT3-1 and FT4-1 were found to proactively search for further information or expertise. They were both actively engaged in the training sessions and expressed their willingness to learn more after the training to better assimilate knowledge and provide further assistance to their suppliers. This is also confirmed by A1-1, who mentioned that: "both of them [FT3-1 and FT4-1] are indeed very active and willing to learn and do something".

In terms of the assistance provided by FTs to their STs after the training session in order to pursue further improvements, FT3-1 went beyond all of the other FTs to initiate joint work with her suppliers. As an example, she participated in redesigning the firefighting equipment in one of her suppliers' factories, which she realised (after the training where she had been involved in a discussion with T1-1 and other attendees) was unable to satisfactorily protect the workers. FT3-1 also engaged in reconciliation between the focal firm and her STs. More specifically, FT3-1 outlined her efforts to persuade STs that A1's requirements were reasonable and achievable. She also asked her STs to be open and honest with her instead of spending time 
and money on mock compliance. Her effort paid off as A1-1 confirmed that FT3-1 and her suppliers were doing relatively well in the audits and were proactively responding to the SSD initiative. Thus, dissonance reduction was also only evident from FT3.

\subsection{Social capital and its relevance to boundary-spanning actions}

Table V summarises the social capital exhibited within the four FT-A1 dyads. The table also presents the manifestation of each social capital aspect identified in previous empirical research and that is contextualised for SSD in this research. Relational identification is, to the best of our knowledge, drawn on and contextualised here for the first time in SSD. In general, all three dimensions of social capital exist to some degree in all four FT-A1 dyads. More specifically, structural capital in the form of network tie; cognitive capital in the form of shared language and codes and relational capital in the form of norms are present in all four dyads. These however are the only aspects of social capital present in the FT1-A1 and FT2-A1 dyads whereas a greater variety of cognitive and relational capital aspects exist in the FT3-A1 and FT4-A1 dyads. Section 4.2.1 below presents more detailed findings on the social capital that exists within each FT-A1 dyad before Section 4.2.2 links the social capital within each downstream dyad to the upstream boundary-spanning actions taken by each FT.

[Take in Table V]

\subsubsection{Social capital within each FT-A1 dyad}

All four dyads exhibited at least a basic level of social capital. More specifically, all four FTs have a contractual relationship with A1 as well as newly developed connections with $\mathrm{T} 1$ and other peer FTs via SSD, thereby constituting the same variety of structural capital in the form of network tie within each dyad. All four dyads also reported an improved understanding of sustainability requirements after the training, indicating enhanced cognitive capital in terms of shared language and codes. In terms of relational capital, there was a strong norm - i.e. a shared consensus regarding the importance of audit compliance - within all four dyads. This worked well for motivating FTs to make efforts towards passing audits at the STs in order to maintain their business relationship with the focal firm. For example, FT2-1 confirmed that the audit requirements were reasonable and achievable and talked about several actions, such as training, for cascading compliance requirements to her suppliers. However, this strong consensus reinforces audit-driven thinking and can become a barrier to further improvements beyond compliance. This sometimes discouraged independent thinking and a willingness to 
pursue further improvement even when firms were provided with additional assistance via SSD. For example, some FTs were confused about the intention behind the SSD project and misinterpreted it as a new type of audit or pre-audit tutorial. A1-1 was aware of this situation and explained: "A few suppliers came to ask me if our auditing requirements have changed as there was additional knowledge not relevant to existing audit requirements included in the training".

The four dyads differed in terms of the variety of cognitive and relational capital aspects, with a greater variety of cognitive and relational capital found within the FT3-A1 and FT4-A1 dyads. More specifically, FT3 and FT4 shared the same goal regarding long-term sustainability development with A1. This helped to overcome audit-driven thinking and go beyond compliance, indicating a reasonable level of shared values and goals, thereby enhancing cognitive capital within the two dyads. FT4-1, for example, stated that: "We are not just focusing on passing the audits, we want to keep track of our suppliers regarding their OHS performance and make sure that they are actually practising sustainability on a daily basis instead of just for the sake of passing audits". These two FTs also developed their own standards and requirements in addition to those of A1. In terms of relational capital, FT3 and FT4 showed some level of mutual understanding with A1 regarding the intention behind the SSD project - they believed it would help them improve and keep up-to-date with A1's sustainable development agenda. In addition, they expressed an intention to undertake several activities after the training, indicating the presence of trust and reciprocity.

Moreover, the FT3-A1 dyad had the greatest variety of cognitive and relational capital. Cognitive capital in the form of shared goal regarding the SSD project and top management commitment were only identified between FT3 and A1. More specifically, FT3-1 understood the SSD project as a chance for her to develop knowledge and skills to pursue further improvements in the long-term at the second-tier level, indicating a shared goal regarding the SSD project with A1. With regards to top management commitment, she explained: "Our CEO put a lot of emphasis on OHS issues. We have invested a large amount of money into appropriate equipment, and we are all willing to learn new things, influenced by our CEO”. Meanwhile, relational capital in the form of identification was only evident in the FT3-A1 dyad, where FT3-1 showed a recognition of the values and standards of A1 and asked her suppliers to try to undertake everything required by the focal firm.

Although no evidence of relational identification was found within the remaining FT-A1 dyads, it was identified within the upstream dyad of FT2-ST2. More specifically, FT2 diffused its own values and standards regarding OHS towards ST2 instead of those of A1. As a result, 
ST2-1 did not take any steps towards completing the mandated improvement assignments of A1; instead, she simply followed the instructions received from FT2-1 and filled in the templates without checking the original assignments. Moreover, during the site visit, ST2-1 was not able to answer any questions directly. Instead, all questions relevant to the assignments and corresponding actions were answered on her behalf by FT2-1. In fact, ST2's OHS documents were prepared superficially by ST2-1 and FT2-1 together purely to deal with checks from local authorities and to pass A1's audits.

\subsubsection{Social capital and its impact on boundary-spanning actions}

From Table IV and Table V, it can be seen that with at least a basic variety of each social capital dimension in place, all of the FTs practiced compliance-oriented boundary-spanning actions. However, the FTs differed with regards to their propensity to carry out further improvementoriented boundary-spanning actions, which is explained by differences in the variety of cognitive and relational capital. With the greatest variety of cognitive and relational capital in place between FT3 and A1, FT3 carried out all of the improvement-oriented boundaryspanning actions identified. More specifically, cognitive capital in the form of top management commitment and shared goals regarding the SSD project and relational capital in the form of identification were only identified in the FT3-A1 dyad. This might suggest that these aspects of social capital are necessary for facilitating improvement-oriented actions, as FT3 was the only FT exclusively practicing all improvement-oriented boundary-spanning actions.

In contrast, the least variety of cognitive and relational capital was identified in the FT1-A1 and FT2-A1 dyads, leading to mainly compliance-oriented boundary-spanning actions being conducted. However, FT1 still differed from FT2 in terms of transparency in transferring information to STs. This may be linked to the relational identification that existed within the FT2-ST2 dyad, which resulted in FT2's propensity to filter out information before transferring it to ST2.

\section{Discussion}

In this section, we discuss our empirical findings in relation to the prior literature in order to answer the research question. In doing so, we theorise the impact of social capital in the downstream dyad, i.e. the focal firm-FT dyad, on the upstream boundary-spanning actions taken by FTs in the context of SSD, as depicted in Figure 3 and further explained below. Figure 3 illustrates that the nature of the boundary-spanning actions undertaken by FTs is primarily influenced by the level of cognitive and relational capital in their relationship with the focal 
firm. To facilitate improvement-oriented actions, a higher level of both cognitive and relational capital is needed. Such a conceptual framework provides a platform for further theoretical and empirical advancement of boundary-spanning research in the field of SSD in multi-tier supply chains.

\section{[Take in Figure 3]}

Studying the interactions between the focal firm, first-tier and second-tier suppliers in the context of SSD through the lens of boundary-spanning and social capital theory has enabled us to identify some important research implications. First, while the boundary-spanning construct has previously been mainly applied to study individual boundary-spanners at the interface between an organisation and its external environment (e.g. Chakkol et al., 2018), we apply it at the organisational level within a buyer-FT-ST setting in the context of SSD. Our findings, which are consistent with Wilhelm et al. (2016), shown that because FTs are embedded in both the buyer-FT and FT-ST dyads they are delegated responsibility by the focal firm not only for complying with sustainability requirements at their own sites but also for ensuring requirements are diffused further upstream to STs. This boundary-spanning role is fundamentally built on the network ties (Preston et al., 2017; Alghababsheh and Gallear, 2020) established between the FT and the focal firm. Therefore, we propose our first proposition:

Proposition 1. The structural capital between a focal firm and first-tier supplier provides a foundation for enabling the first-tier supplier to fulfil its boundary-spanning role in SSD.

Second, a categorisation of the boundary-spanning actions taken by FTs in SSD has been proposed based on synthesising relevant literature and empirical substantiating this to provide a more in-depth and nuanced exploration of how FTs play their complex boundary-spanning role in SSD. More specifically, it has been illustrated that compliance-oriented and improvement-oriented boundary-spanning actions are undertaken by FTs in the context of SSD. The categorisation and the specific actions identified expand on the dichotomy between positive and negative boundary-spanning roles proposed by Soundararajan and Brammer (2018). For example, we have found that all FTs engaged in knowledge and information transfer activities but that the level of information transparency differed across FTs according to their purpose and personal interpretation. FTs that primarily focus on passing audits, i.e. that do not share a long-term sustainability goal with the focal firm, tend to carry out compliance- 
oriented actions. Thus, our study adds explanatory power to why FTs carry out the boundaryspanning role in different ways.

Third, this research adds further insight into the distinct impact of cognitive and relational capital aspects on the boundary-spanning actions of FTs in SSD, as depicted in Figure 3. The literature has highlighted the importance of cognitive and relational capital in facilitating knowledge transfer within the buyer-supplier dyad. More specifically, cognitive capital facilitates knowledge exploitation through shared language and codes, which provides access to different parties for knowledge transfer and for clarifying potential benefits (Nahapiet and Ghoshal, 1998), and by establishing shared goals between the focal firm and its FTs for clarifying what is expected and how it will be achieved (Krause et al., 2007). Relational capital is critical in pursuing strategic goals (Villena et al., 2011) as it is the only social capital dimension that motivates knowledge transfer (Nahapiet and Ghoshal, 1998). The existence of social capital in the buyer-supplier dyad is an important factor to consider when it comes to understanding the sustainability-relevant actions carried out at the supplier side (Zhu and Lai, 2019). Furthermore, it is expected that different dimensions and aspects of social capital may affect suppliers' actions in different ways.

Our findings show that shared language and codes primarily only assist in clarifying audit requirements and the need to comply with them, while norms provide consensus between the focal firm and FTs that motivate FTs to meet audit requirements. Such a basic level of cognitive and relational capital leads to compliance-oriented boundary-spanning actions in SSD (as shown by the cases of FT2 and FT1 in Figure 3). This finding is consistent with prior research (e.g. Preston et al., 2017; Alghababsheh and Gallear, 2020), showing that shared language and codes facilitate the communication of explicit requirements and that norms serve as a basis for cooperation.

Moreover, our findings show that in order to drive improvement-oriented boundaryspanning actions there is a need for cognitive shared values and goals. This helps to clarify what is specifically required for sustainability and the SSD project. In addition, when trust and reciprocity are in place, FTs are aware of the need to take more proactive actions to develop STs, which means they go beyond basic compliance (as shown by the case of FT4 in Figure 3). Higher levels of cognitive and relational capital are required to facilitate further improvementoriented actions. For example, in the case of FT3, where there is also identification in place within the FT3-A1 dyad plus a higher level of shared values and goals, FT3 practices all improvement-oriented actions. We thus extend prior studies that have discussed the positive impact of cognitive and relational capital on sustainability-relevant actions and performance at 
the supplier side as a whole (e.g. Alghababsheh and Gallear, 2020) by unpacking these two dimensions of social capital into their specific aspects. Further, while the literature suggests that cognitive capital and relational capital complement each other (Nahapiet and Ghoshal, 1998; Preston et al., 2017) to enhance sustainability efforts (Zhu and Lai, 2019), we provide additional insights into how they jointly work. We show that a combination of a moderate or advanced level of relational and cognitive capital facilitates improvement-oriented actions in SSD. Based on the above analysis, we propose the following:

Proposition 2. The level of cognitive and relational capital affects how the first-tier supplier carries out its boundary spanning role in SSD.

- Proposition 2a. A basic level of both cognitive and relational capital leads to complianceoriented boundary-spanning actions only.

- Proposition 2b. A more advanced level of both cognitive and relational capital enhances the motivation of a first-tier supplier to engage in improvement-oriented boundary-spanning actions.

We have also identified a potential negative impact brought about by relational capital, as proposed in previous research (e.g. Villena et al., 2011), when relational capital is limited to norms only and this is strongly aligned between the two parties. More specifically, with a shared consensus around achieving audit compliance, all four FTs were motivated to carry out routine audit-relevant practices that helped STs pass audits. The norm reinforced complianceoriented thinking and negatively influenced the motivation of FTs to undertake additional actions that sought to further develop STs over time. This finding lends support to previous research on the potential rigidity of norms (e.g. Nahapiet and Ghoshal, 1998; Preston et al., 2017), which can hinder knowledge transfer when the norm is reinforced over time, and on the critical impact of relational capital (Villena et al., 2011). Going beyond audit compliance relied on norms being combined with other aspects of relational and cognitive capital, such as in the case of FT3. Drawing on the above, we propose the following additional proposition:

Proposition 3. A rigid relational norm between a focal firm and first-tier supplier negatively affects the motivation of the first-tier supplier to undertake improvement-oriented boundaryspanning actions in SSD. 
In addition to the findings regarding the impact of social capital within the downstream dyad on the boundary-spanning actions taken by the FTs, our data also provides insights into the impact of the relational capital that exists in the upstream dyad on the way in which FTs carry out boundary-spanning actions. Our findings show that it can be problematic when identification is present in the upstream dyad but not in the downstream dyad, inducing superficial follow-up actions aimed exclusively at achieving compliance in SSD. Specifically, identification was present in the upstream FT2-ST2 dyad but not in the downstream FT2-A1 dyad. As a result, ST2 was prepared to adopt whatever FT2 suggested as the standard but FT2 was purusing its own self-interest rather than acting purely on behalf of A1.

\section{Conclusions}

The challenges faced by focal firms in managing sustainability in multi-tier supply chains have contributed to the transfer of responsibility for the sustainability of upper supply chain tiers from focal firms to FTs (Soundararajan and Brammer, 2018). Research, however, has only just begun to explore the contingencies (e.g. Wilhelm et al., 2016) or behavioural factors (e.g. Soundararajan and Brammer, 2018) that affect the boundary-spanning role of FTs in diffusing sustainability initiatives up the chain to STs. Our study builds on prior studies by shedding light on the boundary-spanning actions taken by FTs in extending SSD initiatives to STs and how social capital affects the way in which FTs leverage knowledge from SSD in fulfilling their boundary-spanning role.

\subsection{Implications for Research}

In answering our research question, we found that social capital plays an important role in determining how FTs practice boundary-spanning actions related to SSD. The complexity of the sustainability dimension of SSD, which can extend beyond contractual bonds, makes the success of SSD particularly reliant on relation-specific assets, i.e. social capital. In general, the level of cognitive and relational capital affects how first-tier suppliers carry out boundaryspanning actions in SSD. More specifically, cognitive capital in the form of shared values and goals, and relational capital in the form of trust and reciprocity and identification facilitate improvement-oriented boundary-spanning actions in SSD. Meanwhile, excessive relational capital, for example, in the form of a rigid norm that represents a strong agreement on audit compliance only, can generate unfavourable impacts.

Our study also highlights differences in terms of how FTs practice boundary-spanning actions in the context of a social SSD project. FTs undertook either improvement or 
compliance-oriented actions to diffuse SSD initiatives further upstream. Personal interpretation, for example, was added by some FTs, leading to compliance-oriented actions. Overall, this paper makes three main contributions:

1. It provides a refined and substantiated version of the boundary-spanning role fulfilled by FTs in extending social SSD initiatives up the supply chain, achieved by empirically grounding the study in a social SSD project in a multi-tier supply chain. It thus contributes to the boundary-spanning literature by applying this concept to theorise on the role of FTs in SSD given their unique position between the focal firm and second tier. It also extends prior literature on multi-tier sustainable supply chain management (e.g. Soundararajan and Brammer, 2018) by adding greater granularity to the boundaryspanning role and actions.

2. It examines the impact of social capital on the boundary-spanning role of FTs. Specifically, this contribution stems from unpacking the impact of different levels of relational and cognitive capital and their combination on how FTs leverage the knowledge gained from SSD in carrying out boundary-spanning actions related to SSD. To the authors' knowledge, this is the first study to systematically examine the impact of social capital aspects and their interrelationship in such detail. In doing so, it also contributes to the wider SD literature (e.g. Krause et al., 2007; Preston et al., 2017) that has identified the impact of social capital on operational performance by taking into consideration sustainability-relevant performance.

3. It improves our understanding of the potential negative impact of excessive relational capital, as suggested in previous research (e.g. Villena et al., 2011). Our findings provide new insight by showing that excessive relational capital is problematic and can reinforce compliance-oriented thinking in FTs, thereby undermining the effectiveness of SSD initiatives.

\subsection{Implications for Managers}

To improve the effectiveness of SSD projects, focal firms need to be aware of the cognitive and relational capital that resides in their relationships with FTs. These two dimensions of social capital exert a major impact on how FTs benefit from SSD and how they undertake their boundary-spanning role related to SSD. For example, developing a shared sustainability goal, especially regarding the SSD project with FTs, contributes to enabling FTs to provide improvement-oriented assistance to STs thereby going beyond simply achieving audit compliance. Meanwhile, focal firms also need to be aware of the level of relational capital in 
order to avoid any potential negative consequences resulting from excessive levels. This extends to the relational capital residing in the FT-ST dyad as relational capital that exists only in the FT-ST dyad but not the focal firm-FT dyad can negatively affect the upstream diffusion of SSD initiatives.

\subsection{Limitations}

The scope of this research was limited to a particular social SSD project in the apparel sector. Future research could examine if the conclusions apply to other contexts, such as environmental SSD projects, and to other industry sectors. Meanwhile, longitudinal research is needed to examine the connection between different types of boundary-spanning actions and performance outcomes at STs. The role of external knowledge providers such as T1 also warrants further in-depth investigation. Furthermore, it would be interesting to explore how internal alignment between the purchasing and sustainability functions affects the way in which the boundary-spanning role is performed. Unlike traditional SD, business and contractual issues and developmental issues in the context of SSD may be handled separately by the purchasing and sustainability departments, respectively. This can lead to different and sometimes conflicting means of interacting with suppliers (Villena and Gioia, 2020), which can negatively affect the willingness of FTs to accept responsibility for diffusing sustainability practices to STs (Wilhelm et al., 2016). Moreover, the present study could be extended to include a detailed investigation into the social capital within the upstream dyad, how this interacts with the social capital in the downstream dyad, and how the two jointly affect the boundary-spanning actions of the FTs. Finally, further analysis could be undertaken via an indepth investigation of the learning and knowledge application process during SSD for both FTs and STs.

\section{References}

Aldrich, H., and Herker, D. (1977). "Boundary spanning roles and organization structure", Academy of management review, Vol. 2, No. 2, pp. 217-230.

Alghababsheh, M. and Gallear, D. (2020), “Socially Sustainable Supply Chain Management and Suppliers' Social Performance: The Role of Social Capital”, Journal of Business Ethics, pp. 1-21.

Barratt, M., Choi, T. Y. and Li, M. (2011). "Qualitative case studies in operations management: Trends, research outcomes, and future research implications”, Journal of Operations Management, Vol. 29, No. 4, pp. 329-342.

Busse, C., Schleper, M. C., Niu, M. and Wagner, S. M. (2016), “Supplier development for sustainability: contextual barriers in global supply chains", International Journal of Physical Distribution and Logistics Management, Vol. 46, No. 5, pp. 442-468.

Carter, C. R. and Rogers, D. S. (2008), “A framework of sustainable supply chain management: moving toward 
new theory. International Journal of Physical Distribution and Logistics Management, Vol. 38, No. 5, pp. 360387.

Chakkol, M., Karatzas, A., Johnson, M. and Godsell, J. (2018), "Building bridges: boundary spanners in servitized supply chains", International Journal of Operations and Production Management, Vol. 38, No.2, pp. 579-604.

Eisenhardt, K. M. (1989), "Building theories from case study research", Academy of management review, Vol. 14, No. 4, pp. 532-550.

Grimm, J. H., Hofstetter, J. S. and Sarkis, J. (2014), "Critical factors for sub-supplier management: A sustainable food supply chains perspective”, International Journal of Production Economics, Vol. 152, pp. 159-173.

Huang, Y., Luo, Y., Liu, Y. and Yang, Q. (2016), “An Investigation of Interpersonal Ties in Interorganizational Exchanges in Emerging Markets: A Boundary-Spanning Perspective", Journal of Management, Vol. 42, No. 6, pp. 1557-1587.

Huq, F. A. and Stevenson, M. (2020), "Implementing Socially Sustainable Practices in Challenging Institutional Contexts: Building Theory from Seven Developing Country Supplier Cases", Journal of Business Ethics, Vol. 161, No. 2, pp. 415-442.

Inkpen, A. C. and Tsang, E. W. (2005), "Social capital, networks, and knowledge transfer", Academy of Management Review, Vol. 30, No. 1, pp. 146-165.

Ketokivi, M. and Choi, T. (2014), "Renaissance of case research as a scientific method", Journal of Operations Management, Vol. 32, No.5, pp. 232-240.

Krause, D. R., Handfield, R.B. and Tyler, B.B. (2007), "The relationships between supplier development, commitment, social capital accumulation and performance improvement", Journal of Operations Management, Vol. 25, No. 2, pp. 528-545.

Liu, L., Zhang, M., Hendry, L. C., Bu, M. and Wang, S. (2018), "Supplier Development Practices for Sustainability: A Multi-Stakeholder Perspective”, Business Strategy and the Environment, Vol. 27, No. 1, pp. 100-116.

Marrone, J. A. (2010), "Team Boundary Spanning: A Multilevel Review of Past Research and Proposals for the Future", Journal of Management, Vol. 36, No. 4, pp. 911-40.

Mena, C. and Schoenherr, T. (2020), "The green contagion effect: an investigation into the propagation of environmental practices across multiple supply chains tiers", International Journal of Production Research, pp. 1-18.

Nahapiet, J. and Ghoshal, S. (1998), "Social capital, intellectual capital, and the organisational advantage", Academy of Management Review, Vol. 23, No. 2, pp. 242-266.

Nike (2020) "FY20 NIKE, Inc. Impact Report". Available at: https://purpose.nike.com/fy20-nike-impact-report [Accessed 07 April 2021].

Preston, D. S., Chen, D. Q., Swink, M. and Meade, L. J. D. S. (2017), “Generating supplier benefits through buyer-enabled knowledge enrichment: a social capital perspective”, Decision Sciences, Vol. 48, No. 2, pp. 248-287.

Rodríguez, J. A., Giménez Thomsen, C., Arenas, D. and Pagell, M. (2016), "NGOs' initiatives to enhance social sustainability in the supply chain: Poverty alleviation through supplier development programs", Journal of Supply Chain Management, Vol. 52, No. 3, pp. 83-108.

Rogers, Z. S., Carter, C. R. and Kwan, V. (2019), "Making tough choices: A policy capturing approach to evaluating the tradeoffs in sustainable supplier development initiatives", Journal of Purchasing and Supply 
Management, Vol. 25, No. 5, pp. 1-12.

Sauer, P. C. and Seuring, S. (2018), “A three-dimensional framework for multi-tier sustainable supply chain management”, Supply Chain Management: An International Journal, Vol. 23, No. 6, pp. 560-572.

Schotter, A. P. J., Mudambi, R., Doz, Y. L. and Gaur, A. (2017), "Boundary Spanning in Global Organizations”, Journal of Management Studies, Vol. 54, No. 4, pp. 403-421.

Soundararajan, V. and Brammer, S. (2018), "Developing country sub-supplier responses to social sustainability requirements of intermediaries: Exploring the influence of framing on fairness perceptions and reciprocity" Journal of Operations Management, Vol. 58-59, pp. 42-58.

Tachizawa, E. M. and Wong, C. Y. (2014), “ Towards a theory of multi-tier sustainable supply chains: A systematic literature review", Supply Chain Management: An International Journal, Vol. 19, pp. 643-653.

Villena, V. H., Revilla, E. and Choi, T. Y. (2011), “The dark side of buyer-supplier relationships: A social capital perspective”, Journal of Operations Management, Vol. 29, No. 6, pp. 561-576.

Villena, V. H. and Gioia, D. A. (2020), “A more sustainable supply chain”, Harvard Business Review, Vol. 98, No. 2, pp. 84-93.

Voss, C., Johnson, M. and Godsell, J. (2016), "Case research", in Karlsson C. (2 ${ }^{\text {nd }}$ Ed.) Research methods for operations management, Routledge, London, pp.165-198.

Wilhelm, M. M., Blome, C., Bhakoo, V. and Paulraj, A. (2016), "Sustainability in multi-tier supply chains: Understanding the double agency role of the first-tier supplier”, Journal of Operations Management, Vol. 41, pp. $42-60$.

World Trade Organization (2020) “World Trade Statistical Review 2020". Available at: https://www.wto.org/english/res_e/statis_e/wts2020_e/wts20 toc_e.htm [Accessed 07 April 2021].

Yin, R. K. (2018). Case study research: design and methods. $6^{\text {th }}$ ed, SAGE Publications, London.

Zhang, M., Pawar, K. S. and Bhardwaj, S. (2017), "Improving supply chain social responsibility through supplier development", Production Planning and Control, Vol. 28, No. 6-8, pp. 500-511.

Zhang, C., Viswanathan, S. and Henke, J. W. (2011), “The boundary spanning capabilities of purchasing agents in buyer-supplier trust development”, Journal of Operations Management, Vol. 29, No. 4, pp. 318-328.

Zhu, Q. and Lai, K.-H. (2019), "Enhancing supply chain operations with extended corporate social responsibility practices by multinational enterprises: Social capital perspective from Chinese suppliers", International Journal of Production Economics, vol. 213, pp. 1-12.

\section{Appendix}

Interview questions for the focal firm:

1. Please briefly introduce the goal and objectives of this project. Are there any further work plans after this project?

2. Please explain why first-tier suppliers and second-tier suppliers were included in this project.

3. Please describe and evaluate the role played by the external knowledge provider in the SSD project.

4. How long have you been doing business with each of the chosen first-tier suppliers? How would you describe your dependence on them? How do you access your second-tier suppliers?

5. Please describe the level of engagement in the project by [one of the four chosen first-tier suppliers].

6. Please describe and evaluate the work undertaken by [one of the four chosen first-tier suppliers] in supporting the second-tier.

Interview questions for first-tier suppliers: 
1. What do you usually do to communicate the requirements from the brand to the second tier?

2. What do you understand to be the goal of this SSD project?

3. How would you describe your relationship with the brand? Has it changed because of the SSD project?

4. How would you evaluate the role of the external knowledge provider? How would you describe your assimilation of the knowledge delivered?

5. Do you have any work plans after the training both for yourselves and for second tier?

6. How do you plan to further support or monitor the second tier?

\section{Interview questions for second-tier suppliers:}

1. Please evaluate the training session. How would you describe your assimilation of the knowledge delivered? Is there anything you think should be improved?

2. What do you understand to be the goal of this SSD project?

3. How do you manage the sustainability issues in your firm? How do you work with the first tier?

4. Have you had any interactions with the first-tier supplier after the training session?

5. How do you find the mandated tasks? Have you been able to accomplish them?

Interview questions for the external knowledge provider:

1. How would you describe your role in such projects? And in this project, in particular?

2. What do you understand to be the respective goal of the brand and the suppliers in this SSD project?

3. How would you evaluate this project?

4. How would you evaluate the level of engagement of the participants in the training and on-site consultations?

5. Please describe and evaluate the work done by [one of the four chosen first-tier suppliers] in supporting the second tier. 


\section{Tables and Figures}

Table I. Definition of social capital aspects

\begin{tabular}{lll}
\hline $\begin{array}{l}\text { Social capital } \\
\text { dimensions }\end{array}$ & $\begin{array}{l}\text { Social capital } \\
\text { aspects }\end{array}$ & $\begin{array}{l}\text { Definition (Nahapiet and Ghoshal, 1998; Inkpen and Tsang, 2005; } \\
\text { Krause et al., 2007) }\end{array}$ \\
\hline $\begin{array}{l}\text { Structural } \\
\text { capital }\end{array}$ & Network tie & $\begin{array}{l}\text { The fundamental aspect of social capital that deals with the specific } \\
\text { ways in which network members are related. }\end{array}$ \\
\hline $\begin{array}{l}\text { Cognitive } \\
\text { capital }\end{array}$ & $\begin{array}{l}\text { Shared language } \\
\text { and codes } \\
\text { Shared values } \\
\text { and goals }\end{array}$ & $\begin{array}{l}\text { A conduit to exchange, preserve and combine sets of meaning through } \\
\text { shared vocabulary and terminology. } \\
\text { When members within a network have similar perceptions of how they } \\
\text { should interact with one another. }\end{array}$ \\
\hline \multirow{2}{*}{$\begin{array}{l}\text { Rerms } \\
\text { capital }\end{array}$} & $\begin{array}{l}\text { The degree of consensus within a network. } \\
\text { reciprocity }\end{array}$ & $\begin{array}{l}\text { Belief in the good intentions and concerns of exchange partners and a } \\
\text { commitment or duty to undertake some activity in the future. } \\
\text { The process whereby members take the values or standards of other } \\
\text { members or groups as a comparative frame of reference. }\end{array}$ \\
\hline
\end{tabular}


Table II. Indicators of research quality in this study: Validity and reliability

\begin{tabular}{|c|c|c|c|c|}
\hline \multirow{2}{*}{ Criteria } & \multicolumn{4}{|c|}{ Research phase } \\
\hline & Design & Case selection & Data collection & Data analysis \\
\hline $\begin{array}{l}\text { Construct validity } \\
\text { (suitable measures } \\
\text { for the concepts } \\
\text { being studied) }\end{array}$ & $\begin{array}{l}\text { - Interview } \\
\text { questions derived } \\
\text { from previous } \\
\text { research on SSD } \\
\text { - Participate in } \\
\text { the entire SSD } \\
\text { project to access } \\
\text { multiple sources } \\
\text { of data }\end{array}$ & $-\mathrm{N} / \mathrm{A}$ & $\begin{array}{l}\text { - Multiple sources of } \\
\text { information: } \\
\text { interviews, } \\
\text { observation notes } \\
\text { and documentary } \\
\text { data } \\
\text { - Participation in the } \\
\text { training sessions and } \\
\text { on-site } \\
\text { consultations, and } \\
\text { observing the } \\
\text { interactions between } \\
\text { the actors }\end{array}$ & $\begin{array}{l}\text { - Triangulate data } \\
\text { from multiple } \\
\text { sources } \\
\text { - Data coding in an } \\
\text { abductive way to } \\
\text { allow for emerging } \\
\text { topics } \\
\text { - Case study report } \\
\text { validated by } \\
\text { informants to avoid } \\
\text { researchers' bias }\end{array}$ \\
\hline $\begin{array}{l}\text { Internal validity } \\
\text { (causal relationships } \\
\text { between variables } \\
\text { and results) }\end{array}$ & $\begin{array}{l}\text { - Develop a } \\
\text { framework based } \\
\text { on well- } \\
\text { established } \\
\text { boundary- } \\
\text { spanning and } \\
\text { social capital } \\
\text { literature }\end{array}$ & $-N / A$ & $\begin{array}{l}\text { - Choose the most } \\
\text { knowledgeable } \\
\text { informants as } \\
\text { interviewees from } \\
\text { multiple actors } \\
\text { - Interviews fully } \\
\text { transcribed and sent } \\
\text { to interviewees for } \\
\text { checking } \\
\text { - Observation and } \\
\text { diary notes focus on } \\
\text { the actions of, and } \\
\text { the relationship } \\
\text { resources between, } \\
\text { actors }\end{array}$ & $\begin{array}{l}\text { - Record alternative } \\
\text { explanations } \\
\text { - Enfold results into } \\
\text { the boundary- } \\
\text { spanning, social } \\
\text { capital and SSD } \\
\text { literature } \\
\text { - Go back and forth } \\
\text { between the data and } \\
\text { the literature to avoid } \\
\text { researcher bias }\end{array}$ \\
\hline $\begin{array}{l}\text { External validity } \\
\text { (generalizability of } \\
\text { the findings) }\end{array}$ & $\begin{array}{l}\text { - Select a highly } \\
\text { relevant industry } \\
\text { with major social } \\
\text { sustainability } \\
\text { risks } \\
\text { - Multiple case } \\
\text { study design }\end{array}$ & $\begin{array}{l}\text { - Literal } \\
\text { sampling using } \\
\text { replication } \\
\text { logic }\end{array}$ & $\begin{array}{l}\text { - Clearly describe } \\
\text { the case context and } \\
\text { situation } \\
\text { - Conduct interviews } \\
\text { with key informants } \\
\text { - Keep written notes } \\
\text { of the interactions } \\
\text { between, and actions } \\
\text { taken by, the actors }\end{array}$ & $\begin{array}{l}\text { - Pattern-matching } \\
\text { for analytical } \\
\text { generalisation to the } \\
\text { boundary-spanning, } \\
\text { social capital and } \\
\text { SSD literature }\end{array}$ \\
\hline $\begin{array}{l}\text { Reliability } \\
\text { (replicability of the } \\
\text { research design and } \\
\text { results) }\end{array}$ & $\begin{array}{l}\text { - Develop a case } \\
\text { study protocol } \\
\text { and database }\end{array}$ & $\begin{array}{l}\text { - Record case } \\
\text { selection } \\
\text { criteria } \\
\text { - Specify the } \\
\text { sources of data } \\
\text { to be collected }\end{array}$ & $\begin{array}{l}\text { - Develop a semi- } \\
\text { structured interview } \\
\text { schedule, and record } \\
\text { all interviews } \\
\text { - Keep a written } \\
\text { record of the } \\
\text { observation notes } \\
\text { and the documents } \\
\text { reviewed }\end{array}$ & $\begin{array}{l}\text { - Discussion of all } \\
\text { interim results } \\
\text { between all } \\
\text { researchers, } \\
\text { including those who } \\
\text { did not collect the } \\
\text { data } \\
\text { - Keep a record of the } \\
\text { coding process in } \\
\text { Nvivo }\end{array}$ \\
\hline
\end{tabular}


Table III. Summary of sample empirical evidence

\begin{tabular}{|c|c|c|}
\hline $\begin{array}{c}\text { Aggregate } \\
\text { theoretical } \\
\text { themes }\end{array}$ & $\begin{array}{l}\text { First-order } \\
\text { codes }\end{array}$ & Sample evidence from a variety of data sources (e.g. interviews, observation notes, and document analysis) \\
\hline \multirow{4}{*}{ 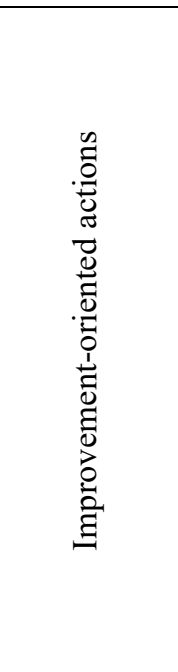 } & $\begin{array}{l}\text { Convey } \\
\text { information } \\
\text { transparently to } \\
\text { STs }\end{array}$ & $\begin{array}{l}\text { "I've passed all the relevant information and materials [for mandated improvements] to them [staff from ST1]." (FT1-1) } \\
\text { All relevant documents and information were found to be passed to both ST1-1 and two other relevant staff from ST1 by FT1-1 during the site visit. } \\
\text { (Observation notes, December 2019) } \\
\text { "In addition, we will share all we have learned from the training with our suppliers and tell them to ask us for help if have any difficulties." (FT3-1) } \\
\text { FT3-1 showed her notes and draft plan to transfer the knowledge to suppliers who did not come to the training. (Observation notes, November 2019) }\end{array}$ \\
\hline & $\begin{array}{l}\text { Proactive search } \\
\text { for further } \\
\text { information or } \\
\text { expertise }\end{array}$ & $\begin{array}{l}\text { "Both of them [FT3-1 and FT4-1] are indeed very active and willing to learn and do something." (A1-1) } \\
\text { "Teachers [T1 and T2] have shared all relevant knowledge with us, we have to learn by ourselves next. I've drafted a plan for the work to be done } \\
\text { and things to learn further." (FT3-1) } \\
\text { "I'll further search relevant material on the internet and further consult the experts if I'm confused about anything." (FT4-1) }\end{array}$ \\
\hline & $\begin{array}{l}\text { Initiate joint } \\
\text { work }\end{array}$ & $\begin{array}{l}\text { "FT3-1 was always highly responsive and quite proactive in investing time and money to ensure the compliance of their suppliers." (A1-1) } \\
\text { "I've contacted an equipment contractor to help redesign the firefighting equipment of one supplier as I now think it needs to be upgraded." (FT3-1) } \\
\text { FT3-1 presented her text messages and phone call records with an equipment contractor during the interview. (Observation notes, October 2019) }\end{array}$ \\
\hline & $\begin{array}{l}\text { Dissonance } \\
\text { reduction } \\
\text { between the focal } \\
\text { firm and STs }\end{array}$ & $\begin{array}{l}\text { "I often tell my suppliers to be frank and honest with me in terms of any problems they have. Do not ask other agencies to help them conceal. I'll try } \\
\text { my best to provide assistance and also check with my clients [A1] to see how we should address the problems" (FT3-1) } \\
\text { "I told my suppliers to cherish this opportunity [to participate in this SSD project], we can learn a lot of useful knowledge without needing to pay. I } \\
\text { told them this is very important as OHS issues are of vital interest to every worker." (FT3-1) }\end{array}$ \\
\hline \multirow{2}{*}{ 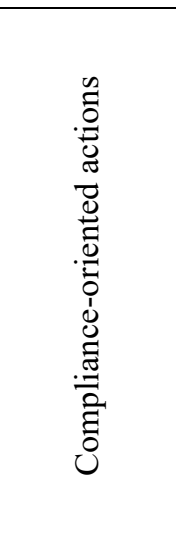 } & $\begin{array}{l}\text { Routine audit- } \\
\text { relevant practices }\end{array}$ & $\begin{array}{l}\text { Both FT1-1 and FT2-1 kept carrying out routinized interactions with their suppliers; however, these were mainly based on the auditing requirements } \\
\text { from A1. (Observation notes, December 2019) } \\
\text { "I have visited my STs as usual and helped them with the mandated improvement assignments." (FT1-1) } \\
\text { "It requires continuous interactions and monitoring on a daily basis." (FT2-1) } \\
\text { "My suppliers and I attended lots of training sessions focusing on achieving auditing compliance in the past." (FT3-1) } \\
\text { "We've got our own COC [code of conduct] which is constituted of all basic audit requirements from various customers to make sure our suppliers } \\
\text { could meet the [audit] requirements from all customers...we are the main player to carry out routinized monitoring and management." (FT4-1) } \\
\text { "It is always the FTs who directly contact us in terms of SSD or audits, he [FT1-1] regularly visited us, especially during audits." (ST1-1) } \\
\text { "Our annual fire drill is usually carried out with the help of her [FT2-1 and her team]." (ST2-1) }\end{array}$ \\
\hline & $\begin{array}{l}\text { Superficial } \\
\text { follow-up actions }\end{array}$ & $\begin{array}{l}\text { "I gave them the forms you gave me for them to work on." (FT1-1) } \\
\text { "I provided them [STs] with samples and templates for them to use as references." (FT2-1) } \\
\text { FT1-1 didn't help ST1-1 as it is found that he didn't clearly know how to work on the mandated tasks and was not able to provide genuine help to } \\
\text { his ST; FT2-1 provided wrong samples to ST2-1 and didn't take it seriously at all (Observation notes, December 2019). }\end{array}$ \\
\hline
\end{tabular}




\begin{tabular}{|c|c|c|}
\hline & $\begin{array}{l}\text { Filter } \\
\text { information to } \\
\text { STs based on } \\
\text { personal } \\
\text { interpretation }\end{array}$ & $\begin{array}{l}\text { "From my point of view, their factories [ST2] don't have a high risk in terms of noise or dust, so they don't need to worry about the occupational } \\
\text { health assessment for workers" (FT2-1) } \\
\text { During the on-site consultation, FT2-1 kept making excuses (e.g. overlap in STs with other FTs; low worker awareness, etc.) for the reason why she } \\
\text { paid more attention during the audits only. (Observation notes, December 2019) } \\
\text { "When I provide training [to suppliers], I won't tell them any national standard/law or associated penalties, I feel like it's too much [abstract] for } \\
\text { them, I'll only let them know what is required by audits." (FT4-1) } \\
\text { FT4-1 kept raising very specific problems he has in his supplier factories. He wanted his suppliers to get more operational guidance from the } \\
\text { training for the sake of passing the audit, rather than improvements on awareness. (Observation notes, November 2019) }\end{array}$ \\
\hline & $\begin{array}{l}\text { Strike } \\
\text { compromises } \\
\text { mainly for the } \\
\text { interest of STs } \\
\text { and themselves }\end{array}$ & $\begin{array}{l}\text { "For most of the STs, they've got a really poor situation [infrastructure] which makes them can hardly benefit from such training." (FT1-1) } \\
\text { "We really need to be informed in advance before formal audits and I need time to get to know those factories. I have to provide them with } \\
\text { templates or samples, otherwise they don't know what to do. Besides, you cannot really raise everyone's awareness." (FT2-1) } \\
\text { FT2-1 listed several difficulties that she thought make it impossible to pursue further improvement during the site visit to her supplier, ST2. } \\
\text { (Observation notes, December 2019) } \\
\text { "What we really need from such training is to help us address the problems from previous audits one by one. I don't think they [STs] need to know } \\
\text { those national standards sort of thing." (FT4-1) }\end{array}$ \\
\hline 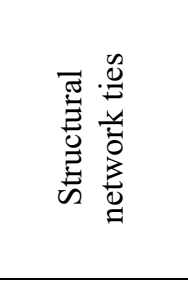 & $\begin{array}{l}\text { Access to T1; } \\
\text { Peer network; } \\
\text { Dedicated staff }\end{array}$ & $\begin{array}{l}\text { "We can get in touch [with T1] if needed. We [FT1 and ST1] also had some chat with A1 and other suppliers." (FT1-1) } \\
\text { FT2-1 is the CSR Manager of FT2 who is in charge of all CSR relevant issues. (Observation notes, October 2019) } \\
\text { "They [A1 and T1] provided us with the access to communication afterwards, e.g. the chatgroup." (FT3-1) } \\
\text { "The teachers [T1 and T2] delivered a really good training ... We had a chance to meet other suppliers [FTs]" (FT4-1) } \\
\text { "We offer technical support to the project. We helped A1 finalize the content and delivery format after several rounds of discussion." (T1-1, T2-1) } \\
\text { The concentrated training session provided many informal communicating opportunities. Some attendees stayed in the same hotel; others had lunch } \\
\text { and dinner gatherings where they discussed the challenges they faced and actions taken. (Observation notes, October/November 2019) }\end{array}$ \\
\hline 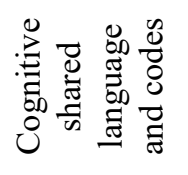 & $\begin{array}{l}\text { Improved } \\
\text { understanding of } \\
\text { the requirements }\end{array}$ & $\begin{array}{l}\text { "For me, it [the training] enhanced my understanding of relevant knowledge of the national standards." (FT2-1) } \\
\text { "I've learned a lot from the training, it's really standardised and professional, we've learned a lot." (FT3-1) } \\
\text { "It [the training] is really good in terms of the suggestions on management skills and provided a systematic view for OHS work." (FT4-1) } \\
\text { All attendees scored over } 70 \% \text { on the test after the training session. (Summary and analysis of the test and feedback, November 2019) }\end{array}$ \\
\hline \multirow{2}{*}{ 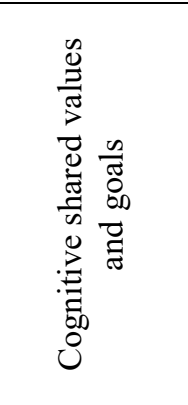 } & $\begin{array}{l}\text { Shared } \\
\text { sustainability } \\
\text { goal }\end{array}$ & $\begin{array}{l}\text { "He [FT4-1] indeed wants to make some efforts, but in a more straightforward way [auditing-driven focus] ... She (FT3-1) is always very responsive } \\
\text { to our requirements. And I know that her boss is taking OHS management very seriously. They've invested a lot on infrastructure" (A1-1) } \\
\text { "OHS issues are relevant to human beings' lives; we have to take it seriously." (FT3-1) } \\
\text { "We are very proactive in terms of OHS issues. I always communicate with A1-1 and ask her to provide us more such training sessions which } \\
\text { involve not only us but also our suppliers [STs] together to let them [STs] directly access the requirements and learn." (FT4-1) } \\
\text { Both FT3-1 and FT4-1 had an aligned understanding with A1-1 about the need to manage OHS issues and a long-term goal of sustainability in } \\
\text { general. (Observation notes, November 2019) }\end{array}$ \\
\hline & $\begin{array}{l}\text { Top management } \\
\text { commitment }\end{array}$ & $\begin{array}{l}\text { "I know that her [FT3-1] CEOs all put a lot emphasis on this, and I know she has made a lot of efforts as well." (A1-1) } \\
\text { "Our CEO put a lot of emphasis on OHS issues. We have invested a large amount of money into appropriate equipment, and we are all willing to } \\
\text { learn new things, influenced by our CEO." (FT3-1) }\end{array}$ \\
\hline
\end{tabular}




\begin{tabular}{|c|c|c|}
\hline & $\begin{array}{l}\text { Shared goals } \\
\text { regarding the } \\
\text { SSD project }\end{array}$ & $\begin{array}{l}\text { "I really cherish the chance to get such a good training. We can learn relevant knowledge without having to pay. What is more important, from my } \\
\text { perspective, is to apply the knowledge to our daily operations; we are not here to find solutions for passing audits." (FT3-1) } \\
\text { A1-1 was frustrated about the fact that some of the attendees do not understand her intention to deploy this SSD project and understood this project } \\
\text { as a different format of pre-audit tutorial. (Observation notes, November 2019) } \\
\text { Several attendees expressed their feeling that the training is not specific enough to guide them to solve the problems they face, primarily audit non- } \\
\text { compliance, from the follow-up feedback questionnaire. (Summary and analysis of the test and feedback, November 2019) }\end{array}$ \\
\hline$\frac{\mathscr{E}}{\stackrel{0}{0}}$ & $\begin{array}{l}\text { Shared } \\
\text { consensus in } \\
\text { terms of the audit }\end{array}$ & $\begin{array}{l}\text { "They [FTs and STs] are well aware of one thing, that our requirements are reasonable and achievable." (A1-1) } \\
\text { "There are audits every year and we are aware of the checklists and are well-prepared." (ST1-1) } \\
\text { "They [STs] have a basic understanding regarding what is required from the client [A1]." (FT2-1) } \\
\text { "We have installed all relevant personal protective equipment for our workers [as instructed by A1]." (ST2-1) } \\
\text { "Our client's requirements are reasonable and achievable, not like other international standards such as BSCI." (FT3-1) } \\
\text { "Just like he [the boss of A1-1] said, their requirements are practical." (FT4-1) } \\
\text { At the beginning of the training, the manager of the sustainability department [the boss of A1-1] has stated again that their requirements are } \\
\text { reasonable, and all of the attendees have positively responded to this statement. (Observation notes, October 2019) } \\
\text { The keyword throughout the whole training session was 'audit', which seems to be the main issue the attendees care about. (Observation notes, } \\
\text { October/November 2019) }\end{array}$ \\
\hline 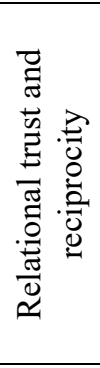 & $\begin{array}{l}\text { Understand SSD } \\
\text { as mutually } \\
\text { beneficial and } \\
\text { take reciprocal } \\
\text { actions }\end{array}$ & $\begin{array}{l}\text { "She [FT3-1] has got a good understanding of what I'm trying to achieve through this SSD project. He [FT4-1] indeed wants to make some efforts, } \\
\text { but in a more straightforward way [auditing-driven focus]." (A1-1) } \\
\text { "We really appreciate our client for providing this chance free of charge for us. It's a shame that not all of my suppliers are able to come...by } \\
\text { attending this training and also interacting with other FTs, I also figured out some deficiencies our suppliers have in their OHS management } \\
\text { scheme...this [the SSD project] really helps a lot..." (FT3-1) } \\
\text { FT3-1 showed me her phone call records and the text messages with subcontractors regarding the planned work to upgrade some of the equipment. } \\
\text { (Observation notes, October 2019) } \\
\text { "We really appreciate that our client [A1] could provide such chances [SSD projects] for us so that we can catch up with the pace of the client } \\
\text { [A1]." (FT4-1) }\end{array}$ \\
\hline 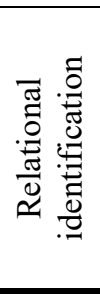 & $\begin{array}{l}\text { Take direct } \\
\text { customer's } \\
\text { values and } \\
\text { standards as the } \\
\text { primary } \\
\text { reference }\end{array}$ & $\begin{array}{l}\text { "As you can see, [ST2-1] does not really care about anything from the training. [FT2-1] would prepare all materials required on her behalf [ST2-1] } \\
\text { and will do cover-ups for her firm [ST2], so [ST2-1] did not have the awareness or the intention to take any actions." (T1-1) } \\
\text { ST2-1 asked FT2-1 for help with any issues raised by A1 or T1 during the on-site consultations. She did not check any of the requirements or details } \\
\text { provided by the trainers during the training; instead, she only worked on the templates and documents provided by FT2. (Observation notes, } \\
\text { December 2019) } \\
\text { "I always tell my suppliers that my client [A1] won't ask us to do anything that we're not capable of. So we need to follow all that required by our } \\
\text { clients; in doing this, we are responsible for all three of us [A1, FT3, FT3's suppliers]" (FT3-1) }\end{array}$ \\
\hline
\end{tabular}


Table IV. Boundary-spanning actions taken by each first-tier supplier

\begin{tabular}{|c|c|c|c|c|c|}
\hline Boundary-spanning actions & $\begin{array}{l}\text { References (novel actions from } \\
\text { our empirical data marked by *) }\end{array}$ & FT1 & FT2 & FT3 & FT4 \\
\hline \multicolumn{6}{|l|}{ Improvement-oriented } \\
\hline Convey information transparently to STs & Zhang et al. (2011) & $\mathrm{x}$ & - & $\mathrm{x}$ & - \\
\hline $\begin{array}{l}\text { Proactively search for further } \\
\text { information or expertise }\end{array}$ & Marone (2010); Soundararajan & - & - & $\mathrm{X}$ & $\mathrm{x}$ \\
\hline Initiate joint work & $\begin{array}{l}\text { Marone (2010); Huang et al. } \\
\text { (2016); }\end{array}$ & - & - & $\mathrm{X}$ & - \\
\hline $\begin{array}{l}\text { Dissonance reduction between the focal } \\
\text { firm and STs }\end{array}$ & $\begin{array}{l}\text { Zhang et al. (2011); Huang et al. } \\
\text { (2016); Chakkol et al. (2018) }\end{array}$ & - & - & $\mathrm{x}$ & - \\
\hline \multicolumn{6}{|l|}{ Compliance-oriented } \\
\hline $\begin{array}{l}\text { Routine audit-relevant practices (e.g. } \\
\text { audit-driven site visits and training } \\
\text { sessions) }\end{array}$ & $\begin{array}{l}\text { Huang et al. (2016); Chakkol et } \\
\text { al. (2018); Soundararajan and } \\
\text { Brammer, } 2018\end{array}$ & $\mathrm{x}$ & $\mathrm{x}$ & $\mathrm{x}$ & $\mathrm{x}$ \\
\hline $\begin{array}{l}\text { Filter information to STs based on } \\
\text { personal interpretation }\end{array}$ & $*$ & - & $\mathrm{x}$ & - & $\mathrm{x}$ \\
\hline Superficial follow-up actions & $\begin{array}{l}\text { Soundararajan and Brammer } \\
\text { (2018) }\end{array}$ & $\mathrm{x}$ & $\mathrm{x}$ & - & - \\
\hline $\begin{array}{l}\text { Strike compromises mainly for the } \\
\text { interest of STs and themselves }\end{array}$ & $*$ & $\mathrm{x}$ & $\mathrm{x}$ & - & $\mathrm{x}$ \\
\hline
\end{tabular}

Table V Social capital within each FT-A1 dyad

\begin{tabular}{|c|c|c|c|c|c|c|}
\hline $\begin{array}{l}\text { Social capital } \\
\text { dimensions and } \\
\text { aspects }\end{array}$ & $\begin{array}{l}\text { Manifestations from previous } \\
\text { empirical research }\end{array}$ & $\begin{array}{l}\text { Manifestations in this } \\
\text { research }\end{array}$ & $\begin{array}{l}\text { FT1 } \\
-\mathrm{A} 1\end{array}$ & $\begin{array}{l}\text { FT2 } \\
-\mathrm{A} 1\end{array}$ & $\begin{array}{l}\text { FT3 } \\
\text {-A1 }\end{array}$ & $\begin{array}{l}\text { FT4 } \\
-\mathrm{A} 1\end{array}$ \\
\hline $\begin{array}{l}\text { Structural } \\
\text { Network tie }\end{array}$ & $\begin{array}{l}\text { Information sharing (Krause et } \\
\text { al., 2007); Contractual control; } \\
\text { Monitoring control (Zhu and } \\
\text { Lai, 2019) }\end{array}$ & $\begin{array}{l}\text { Access to T1; Dedicated } \\
\text { staff; Peer network }\end{array}$ & $\mathrm{x}$ & $\mathrm{x}$ & $\mathrm{x}$ & $\mathrm{x}$ \\
\hline $\begin{array}{l}\text { Cognitive } \\
\text { Shared language } \\
\text { and codes }\end{array}$ & $\begin{array}{l}\text { Language and codes; } \\
\text { Narratives (Zhu and Lai, } \\
\text { 2019). }\end{array}$ & $\begin{array}{l}\text { Improved understanding of } \\
\text { the requirements }\end{array}$ & $\mathrm{x}$ & $\mathrm{x}$ & $\mathrm{x}$ & $\mathrm{x}$ \\
\hline $\begin{array}{l}\text { Shared values } \\
\text { and goals }\end{array}$ & $\begin{array}{l}\text { Goals and values (Krause et } \\
\text { al., 2007); Degree of similar } \\
\text { visions, ambitions and values } \\
\text { (Preston et al., 2017) }\end{array}$ & $\begin{array}{l}\text { Shared sustainability goal; } \\
\text { Top management } \\
\text { commitment; } \\
\text { Shared goal regarding the } \\
\text { SSD project }\end{array}$ & - & $\begin{array}{l}- \\
- \\
-\end{array}$ & $\begin{array}{l}\mathrm{x} \\
\mathrm{x} \\
\mathrm{x}\end{array}$ & $\begin{array}{l}\mathrm{X} \\
- \\
-\end{array}$ \\
\hline $\begin{array}{l}\text { Relational } \\
\text { Norms }\end{array}$ & $\begin{array}{l}\text { Consensus on how to } \\
\text { cooperate (Preston et al., } \\
\text { 2017) }\end{array}$ & $\begin{array}{l}\text { Shared consensus } \\
\text { regarding audit }\end{array}$ & $\mathrm{x}$ & $\mathrm{x}$ & $\mathrm{x}$ & $\mathrm{x}$ \\
\hline $\begin{array}{l}\text { Trust and } \\
\text { reciprocity }\end{array}$ & $\begin{array}{l}\text { Mutual trust and respect } \\
\text { (Preston et al., 2017); } \\
\text { Reciprocity; Cooperation; } \\
\text { Interaction (Zhu and Lai, } \\
\text { 2019) }\end{array}$ & $\begin{array}{l}\text { Understand SSD as } \\
\text { mutually beneficial and } \\
\text { take reciprocal actions }\end{array}$ & - & - & $\mathrm{X}$ & $\mathrm{x}$ \\
\hline Identification & - & $\begin{array}{l}\text { Take direct customer's } \\
\text { values and standards as the } \\
\text { primary reference }\end{array}$ & - & - & $\mathrm{x}$ & - \\
\hline
\end{tabular}


Figure 1. Overview of the key informants and sources of data

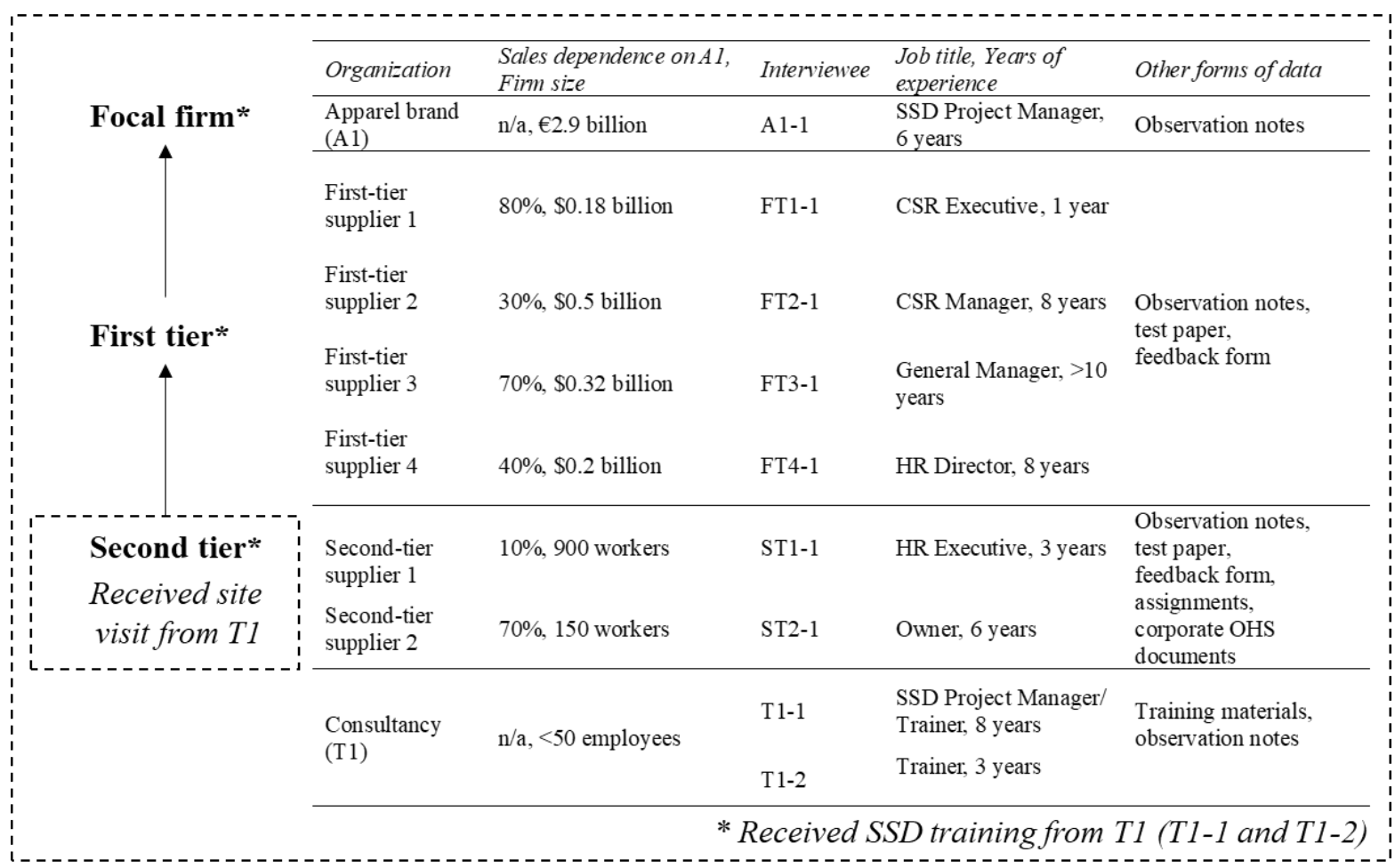


Figure 2. Coding structure

First-order codes
Aggregate theoretical themes

Theoretical dimensions

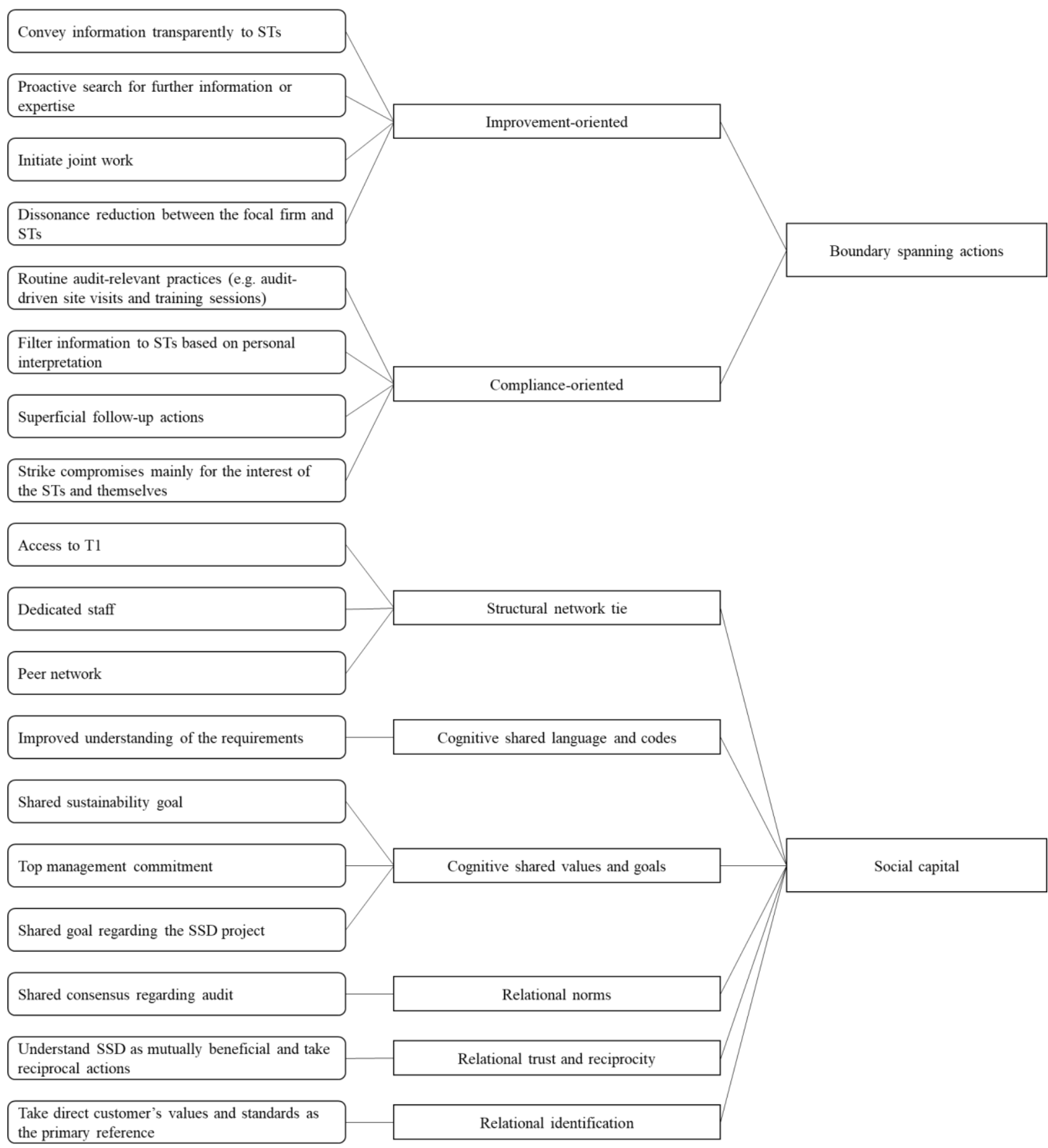


Figure 3. Conceptual framework theorizing the impact of downstream social capital on the upstream boundaryspanning actions of the first-tier supplier

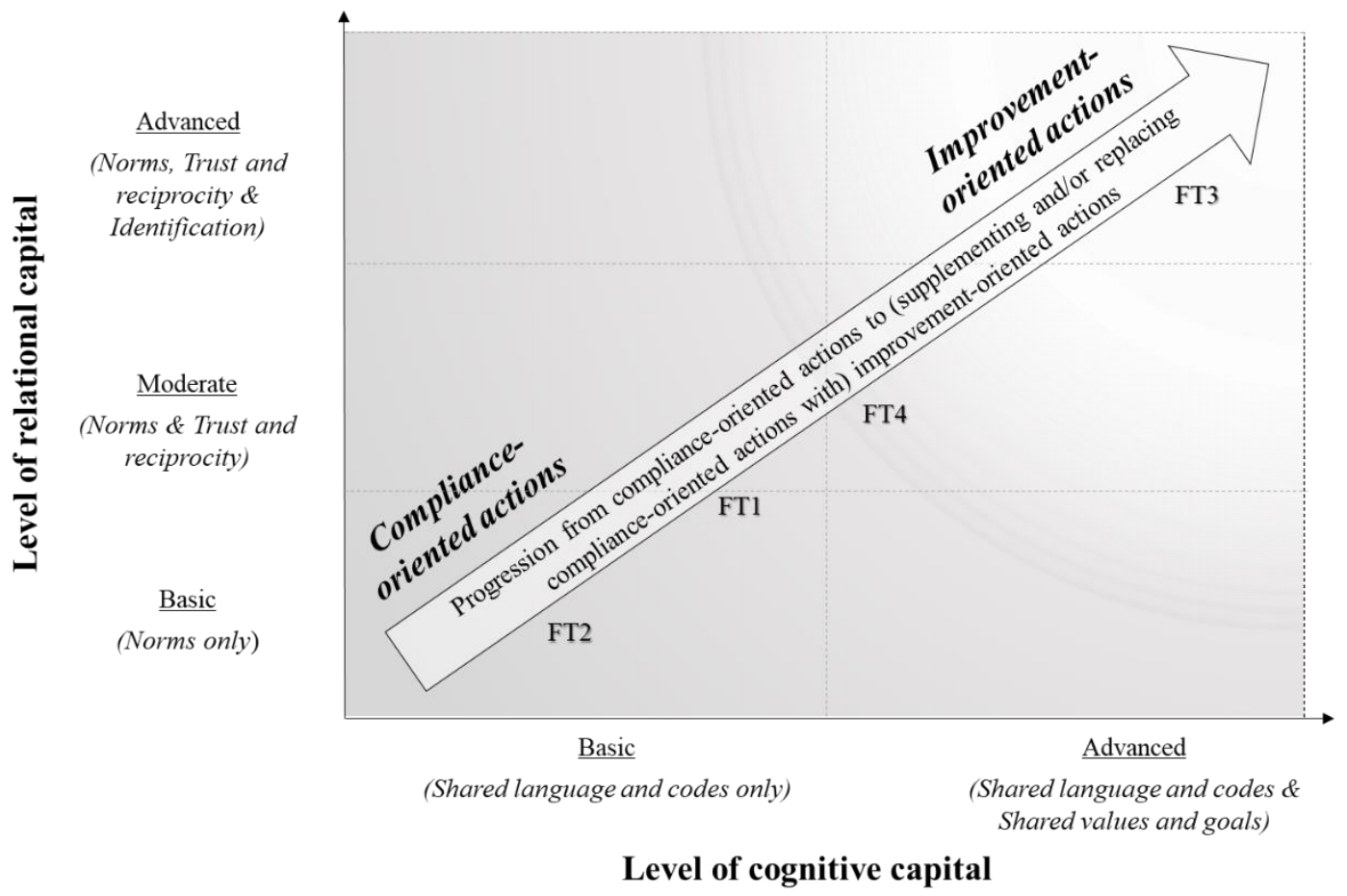

